\title{
IDENTIFIKASI SENYAWA FLAVONOID PADA FRAKSI ETIL ASETAT BENALU BATU(Begonia sp.) ASAL KABUPATEN MOROWALI UTARA
}

\section{IDENTIFICATION OF FLAVONOID COMPOUNDS IN ETHYL ACETATE FRACTION OF BENALU BATU (Begonia Sp.) ORIGINATED FROM NORTH MOROWALI REGENCY}

\author{
Agus Ritna $^{1^{*}}$, Syariful Anam ${ }^{1}$, Akhmad Khumaidi ${ }^{1}$ \\ ${ }^{1}$ Jurusan Farmasi, Fakultas MIPA, Universitas Tadulako, Palu, Indonesia
}

\begin{abstract}
ABSTRAK
Tumbuhan Benalu Batu (Begonia sp.) dari familia Begoniaceae merupakan tanaman yang digunakan oleh masyarakat Morowali Utara untuk mengobati tumor dan kanker.Secara umum tumbuhan Benalu Batu (Begonia sp.) memiliki senyawa saponin, tanin, flavonoid dan polifenol.Penelitian ini bertujuan untuk mengidentifikasi senyawa flavonoid fraksi etil asetat benalu batu (Begonia sp.).Simplisia diekstraksi dengan metode maserasi dan dipartisi dengan meggunakan $n$-heksana, etil asetat dan air.Ekstrak etil asetat difraksinasi dengan sembilan perbandingan eluen, metode pemisahan yang digunakan adalah kromatografi cair vakum $(\mathrm{KCV})$ dan kromatografi lapis tipis preparatif (KLTP).Didapatkan satu fraksi yang diduga memiliki senyawa flavonoid setelah dilakukan uji pereaksi warna dengan metode Shinode dan Pew.Hasil Spektroskopi Ultraviolet-Visible dengan menggunakan pelarut metanol pada rentang panjang gelombang $200-550 \mathrm{~nm}$, isolat menunjukkan puncak serapan pada $275 \mathrm{~nm}$ (puncak 1) dan $225 \mathrm{~nm}$ (puncak 2). Berdasarkan panjang gelombang senyawa flavonoid yang dikandung fraksi benalu batu (Begonia sp.) menunjukkan kemiripan dengan puncak serapan jenis flavan-3-ol atau flavanol.
\end{abstract}

Kata kunci : Begonia sp., Flavonoid, Fraksi etil asetat, flavanol.

\begin{abstract}
Benalu Batu Plant (Begonia sp.) in family Begoniaceae is a plant used by the people of North Morowali to treat tumors and cancers. It generally contains saponins, tannins, flavonoids and polyphenols. This research aimed to identify flavonoid compounds contained in ethyl acetate fraction ofBegonia sp. The simplicia was extracted using maceration method and partitioned using n-hexane, ethyl acetate and water. The Ethyl acetate extract was then fractionated by nine eluent combinations using separation method ofVacuum Liquid Chromatography (VLC) and Preparative Thin Layer Chromatography (Prep TLC). One fraction was obtained and was suspected to contain flavonoid compounds after Shinode and Pew color reagent test. In the result of Ultraviolet-Visible Spectroscopy with methanol at wavelength range of $200-550 \mathrm{~nm}$, the isolates showed absorption peaks at $275 \mathrm{~nm}$ (peak 1) and $225 \mathrm{~nm}$ (peak 2). Based on the wavelength of flavonoid compounds contained in the fraction, Begonia sp.showed similarities to the absorption peak of flavan-3-ol or flavanols.
\end{abstract}

Keywords : Begonia sp., Flavonoids, ethyl acetate fraction, flavanols.

*Coresponding Author : Agus Ritna, agusritnapanganso@gmail.com (ph:+62-853-9522-1340) 


\section{PENDAHULUAN}

Tumbuhan Benalu Batu (Begonia sp.) asal Kab. Morowali Utara, Sulawesi Tengah, merupakan salah satu tumbuhan yang digunakan secara empiris oleh masyarakat untuk mengobati berbagai penyakit. Masyarakat menggunakan tanaman ini untuk pengobatan tumor, kanker (Novriawan, 2009).

Penelitian yang telah dilakukan menyatakan bahwa ekstrak metanol Benalu Batu (Begonia sp.) aktif menghambat pertumbuhan sel kanker dengan memberikan efek hambatan pertumbuhan sel kanker payudara (T47D) dengan nilai $\mathrm{IC}_{50}=122,21$ $\mu \mathrm{g} / \mathrm{ml}$. Selain itu uji antikanker mulut rahim dengan menggunakan sel kanker HeLa ekstrak metanol dapat menghambat pertumbuhan sel kanker HeLa dengan nilai $\mathrm{IC}_{50}=70,97 \mu \mathrm{g} / \mathrm{ml}$ (Anam dkk, 2014)

Hasil uji skrining fitokimia terhadap ekstrak metanol benalu batu (Begonia sp.) diketahui positif mengandung senyawa golongan flavonoid (Anam, dkk, 2014).Senyawa flavonoid diduga memiliki peran dalam menghambat sel kanker T47D dan sel HeLa. Oleh karena itu penelitian identifikasi terhadap golongan senyawa flavonoid dari fraksi etil asetat ekstrak Benalu Batu ini perlu untuk dilakukan.

\section{BAHAN DAN METODE}

\section{Bahan}

Sampel yang digunakan merupakan tumbuhan Benalu Batu (Begonia sp.) yang diambil di desa Wawopada kabupaten Morowali Utara. Bahan yang digunakan adalah pelarut etanol $96 \%$, metanol, $n$-heksana, etil asetat, air suling, lempeng KLT $\mathrm{F}_{254}$ (MERCK), serbuk silika gel $60 \mathrm{PF}_{254}$ (MERCK), serbuk silika $\mathrm{GF}_{254}$ (MERCK), Aluminium klorida, serbuk magnesium dan serbuk zink.

\begin{abstract}
Alat
Gelas ukur, gelas kimia, bejana maserasi, chamber KLT, neraca analitik $\left(\right.$ CITIZEN $\left.^{\circledR}\right)$, timbangan gram $\left(\right.$ OHAUS $\left.{ }^{\circledR}\right)$, hot plate, vacuum rotary evaporator $\left(E Y E L A^{\circledR}\right)$, cawan porselen, oven, sentrifuge (C2 SERIES), lampu UV $245 \mathrm{~nm}$ dan $366 \mathrm{~nm}$ (CAMAG),dan spektrofotometer UV-Vis (UNICO).
\end{abstract}

\section{Identifikasi Tumbuhan}

Sampel tumbuhan yang digunakan diidentifikasi di Unit Pelaksana Teknis (UPT)
Sumber Daya Hayati Sulawesi Tengah Universitas Tadulako Palu.

\section{Penyiapan Ekstrak Uji}

Tumbuhan Begonia sp dicuci dengan air mengalir hingga bersih, dirajang lalu dikeringkan. Simplisia 228,98 gram diserbukkan lalu dimaserasi dengan menggunakan pelarut etanol $96 \%$ sebanyak $2400 \mathrm{ml}$ selama 3x 24 jam lalu diuapkan menggunakan vacuum rotary evaporator pada suhu pemanasan $65^{\circ} \mathrm{C}$ sehingga didapatkan ekstrak kental.

\section{Partisi}

Ekstrak etanol 10 gram dilarutkan dengan etanol $10 \mathrm{ml}$ dan air suling sebanyak $20 \mathrm{ml}$. Kemudian dipartisi dengan $30 \mathrm{ml}$ pelarut $n$ heksana dalam corong pisah sebanyak 6 kali, dan ekstrak $n$-heksana diuapkan dengan vacuum rotary evaporator sehingga diperoleh ekstrak kental $n$-heksana. Dengan menggunakan jumlah pelarut yang sama selanjutnya residu dipartisi dengan pelarut etil asetat. Setelah itu ekstrak etil asetat dan ekstrak air diuapkan pelarutnya hingga diperoleh ekstrak kental etil asetat dan air.

\section{Uji Pereaksi Warna}

$>$ Metode shinode, $1 \mathrm{ml}$ dari ekstrak etil asetat dan n-heksana yang dilarutkan dengan etanol $96 \%$ ditambahkan 100 mg serbuk magnesium, dan diteteskan $0,5 \mathrm{ml}$ asam klorida pekat.

$>$ Metode Pew, $1 \mathrm{ml}$ dari ekstrak etil asetat dan n-heksana yang dilarutkan dengan etanol $96 \%$, ditambahkan 400 mg lempeng zinkdan diteteskan 2 tetes asam klorida $2 \mathrm{~N}$ dan asam klorida pekat sebanyak $0,5 \mathrm{ml}$. Uji shinode dan pew tidak dilakukan pada ekstrak air.

\section{Fraksinasi dengan Kromatografi Cair Vakum (KCV)}

Sampel 1 gram dilarutkan dengan eter dan dipreabsorbsi dengan silika gel $\mathrm{GF}_{254}$ hingga homogen dan kering. Dimasukkan ke dalam kolom yang terisi dengan silika lalu dielusi menggunakan pelarut yang kepolaran semakin meningkat yaitu dengan $n$-heksana, $n$-heksana : etil asetat (3:2), $n$-heksana : etil asetat (1:4), etil asetat, etil asetat : metanol (4:1), etil asetat : metanol (3:2), etil asetat : metanol (2:3), etil asetat : metanol (1:4) dan metanol. 


\section{Identifikasi dengan Pereaksi Semprot pada Lempeng KLT}

Hasil fraksinasi ditotolkan pada lempeng KLT dan disemprot dengan pereaksi $\mathrm{AlCl}_{3}$. Elusi dilakukan menggunakan perbandingan eluen etil asetat : metanol (3:2) yang memberikan profil KLT yang terbaik.

\section{Isolasi dengan KLTP}

hasil fraksinasi dilarutkan dan ditotolkan pada lempeng KLTP kemudian lempeng kaca hasil penotolan dikeringkan dan selanjutnya dielusi dengan etil asetat : metanol (3:2). Setelah dilakukan pengembangan, pita yang terbentuk dikerok dan dipisahkan dari silika gel yang masih terikat.

\section{Uji kemurnian isolat}

Isolat flavonoid yang diperoleh diuji kemurniaannya dengan metode elusi sistem multi eluen. Isolat flavonoid ditotolkan pada lempeng KLT, selanjutnya dielusi menggunakan $n$-heksana : kloroform : etil asetat $(6: 1,5: 1), n$-heksana: kloroform $(3: 1)$, dan $n$-heksana : etil asetat (4:1).

\section{Spektroskopi senyawa isolat}

Isolat murni yang merupakan senyawa flavonoid dilarutkan dalam metanol kemudian diamati spektrumnyamenggunakanspektrofotometer UV-Vis pada rentang panjang gelombang 200$550 \mathrm{~nm}$.

\section{HASIL DAN PEMBAHASAN \\ Identifikasi Tanaman}

Identifikasi yang dilakukan di Unit Pelaksana Teknis (UPT) Sumber Daya Hayati Sulawesi Tengah Universitas Tadulako Palu, menyatakan bahwa sampel yang digunakan untuk penelitian merupakan tumbuhan Begonia sp.

\section{Pembuatan ekstrak uji}

Serbuk simplisia Begonia sp. sebanyak 228,98 gram dimaserasi dengan menggunakan pelarut etanol 96\%. Hasil ekstraksi maserasi didapatkan ekstrak etanol 14,5 gram.

\section{Partisi}

Ekstrak etanol Begonia sp. dipartisi menggunakan dua pelarut yang mempunyai tingkat kepolaran berbeda yaitu $n$-heksana, etil asetat dan air.Diperoleh ekstrak kental $n$ heksana sebanyak 3,40 gram dengan persen rendemen $34 \%$, ekstrak kental etil asetat 1,05 gram dengan persen rendemen $10,5 \%$ dan ekstrak air yang tersisa adalah 3,16 gram dengan persen rendemen $31,6 \%$.

\section{Uji pereaksi warna ekstrak hasil partisi}

Ekstrak larut $n$-heksana dan ekstrak larut etil asetat dikumpulkan, lalu diuji dengan menggunakan reaksi Shinoda dan reaksi Pew. Hasil uji fitokimia ekstrak dapat dilihat padaTabel 1

Tabel 1 Hasil uji fitokimia dengan pereaksi warna ekstrak n-heksana dan etil asetat

\begin{tabular}{|l|l|l|l|l|}
\hline partisi & Reaksi shinode & Ket. & $\begin{array}{l}\text { Reaksi } \\
\text { pew }\end{array}$ & Ket. \\
\hline n-heksana & Hijau kehitaman & - & Hitam & - \\
\hline Etil asetat & merah & + & $\begin{array}{l}\text { Merah, } \\
\text { keunguan }\end{array}$ & + \\
\hline air & ND & ND & ND & ND \\
\hline
\end{tabular}

Ket :

ND : tidak dilakuakn

\section{Fraksinasi dengan kromatografi cair} vakum (KCV)

Setelah proses elusi selesai diperoleh delapan fraksi yaitu F2-F9 dapat dilihat pada tabel 2 .

Tabel 2 hasil pemisahan ekstrak etil setat Begonia sp.

\begin{tabular}{cccc}
\hline Fraksi & Fraksi etil asetat & $\begin{array}{c}\text { Bobot } \\
\text { fraksi } \\
\text { (gram) }\end{array}$ & $\begin{array}{c}\text { Persen } \\
\text { rendam } \\
\text { en }\end{array}$ \\
\hline F1 & Heksan & 0 & $0 \%$ \\
F2 & Heksan : etil asetat (30:20) & 0,12 & $12 \%$ \\
F3 & Heksan : etil asetat (10:40) & 0,08 & $8 \%$ \\
F4 & Etil asetat (50) & 0,13 & $13 \%$ \\
F5 & Etil asetat : metanol (40:10) & 0,15 & $15 \%$ \\
F6 & Etil asetat : metanol (30:20) & 0,16 & $16 \%$ \\
F7 & Etil asetat : metanol (20:30) & 0,09 & $9 \%$ \\
F8 & Etil asetat : metanol (10:40) & 0,12 & $12 \%$ \\
F9 & Metanol (50) & 0,13 & $13 \%$ \\
& Persen recovery & 0,98 & $98 \%$ \\
\hline
\end{tabular}




\section{Identifikasi Dengan Pereaksi Semprot Pada Lempeng KLT}

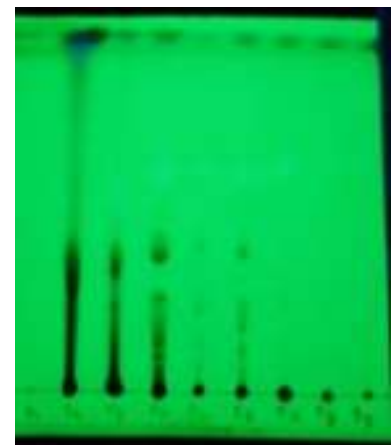

a

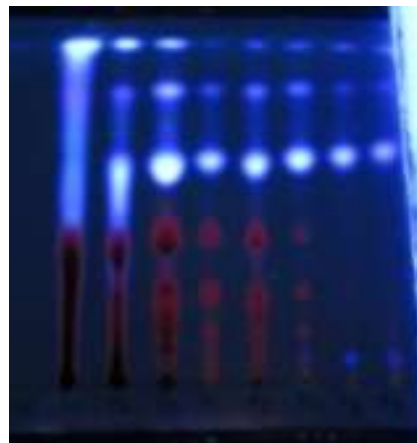

b

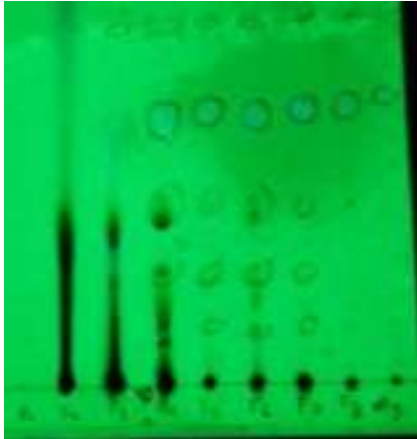

$\mathrm{c}$

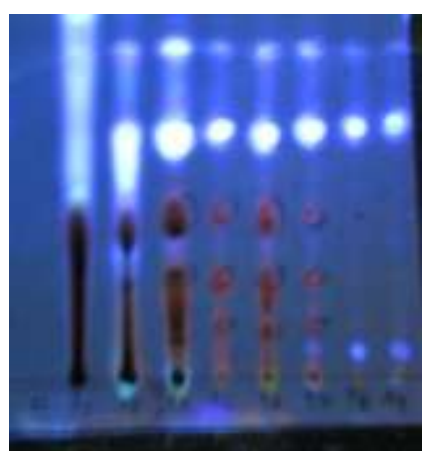

d

Gambar 1 KLT Hasil kromatografi cair vakum dan penyemprotan dengan $\mathrm{AlCl}_{3} 5 \%$;fase diam silica gel $\mathrm{F}_{254}$ dan eluen yang digunakan adalah n-heksan:etil asetat (4:1), pada jarak elusi $8 \mathrm{~cm}$.

a. Visualisasi KLT pada lampu UV $254 \mathrm{~nm}$

b. Visualisasi KLT pada lampu UV $366 \mathrm{~nm}$

c. Visualisasi KLT setelah penyemprotan $\mathrm{AlCl}_{3}$ pada lampu UV $254 \mathrm{~nm}$

d. Visualisasi KLT setelah penyemprotan $\mathrm{AlCl}_{3}$ pada lampu UV 366nm

Tabel 3 Hasil uji pereaksi warna hasil fraksi etil asetat Benalu Batu (Begonia sp.)

\begin{tabular}{clllc}
\hline Fraksi & \multicolumn{1}{c}{ Fraksi etil asetat } & Reaksi Shinode & Reaksi Pew & Ket. \\
\hline F2 & Heksan : etil asetat (30:20) & Hijau, kecoklatan & Hijau & - \\
F3 & Heksan : etil asetat (10:40) & Hijau, hitam & Hijau & - \\
F4 & Etil asetat (50) & Hijau & Hijau & - \\
F5 & Etil asetat : metanol (40:10) & Coklat & Hijau, kecoklatan & - \\
F6 & Etil asetat : metanol (30:20) & Merah bata & Merah bata, keunguan & + \\
F7 & Etil asetat : metanol (20:30) & Cokelat muda & Hijau muda & - \\
F8 & Etil asetat : metanol (10:40) & Cokelat & Hijau bening & - \\
F9 & Metanol (50) & Cokelat keruh & Hijau bening & - \\
\hline
\end{tabular}

\section{Uji Kemurnian Isolat}

Dari pengamatan pada lempeng KLT setelah dielusi dengan tiga perbandingan eluen dengan kepolaran yang berbeda, noda terlihat tunggal Seperti pada gambar 3.

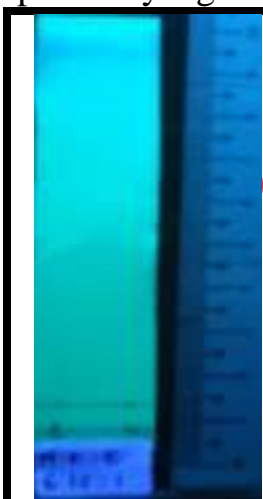

a

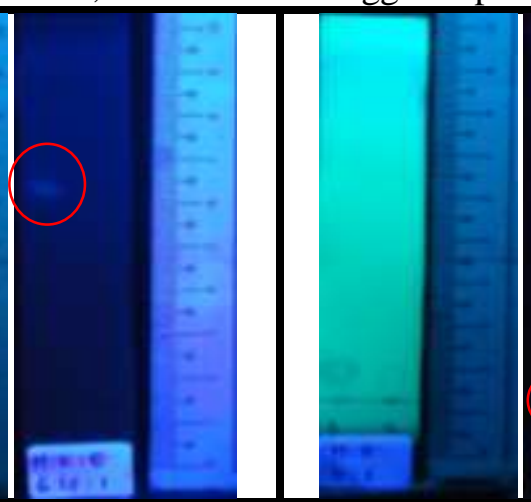

b

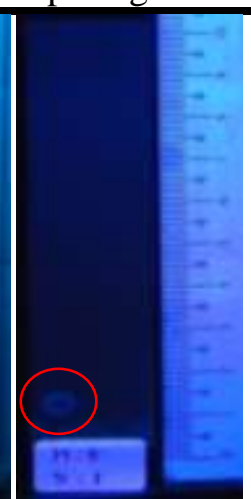

d

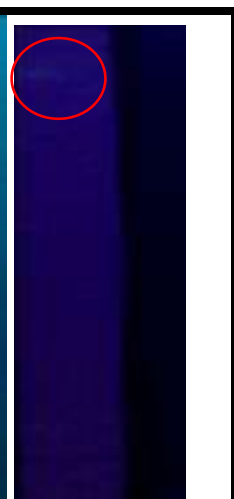

f

Gambar2 Hasil identifikasi senyawa tunggal dengan menggunakan kromatografi lapis tipis multieluen.Fase diam silica gel $\mathrm{F}_{254}$, Pada jarak elusi $8 \mathrm{~cm}$.

a. Penampakan KLT multi eluen $n$-heksan : kloroform : etil asetat $(6: 1,5: 1)$ pada lampu UV 254

b. Penampakan KLT multi eluen $n$-heksan : kloroform : etil asetat $(6: 1,5: 1)$ pada lampu UV 366

c. Penampakan KLT multi eluen $n$-heksan:kloroform (3:1) pada lampu UV $254 \mathrm{~nm}$

d. Penampakan KLT multi eluen $n$-heksan:kloroform (3:1) pada lampu UV $366 \mathrm{~nm}$

e. Penampakan KLT multi eluen $n$-heksan:etil asetat (4:1) pada lampu UV $254 \mathrm{~nm}$ 
f. Penampakan KLT multi eluen $n$-heksan:etil asetat (4:1) pada lampu UV $366 \mathrm{~nm}$

\section{Analisis Spektrofotometri UV-Vis Isolat}

\section{Pembahasan}

Serbuk simplisia Begonia sp. sebanyak 228,98 gram dimaserasi dengan menggunakan pelarut etanol 96\%. Pemilihan etanol sebagai pelarut didasarkan pada etanol bersifat lebih selektif pada senyawa metabolit sekunder, tidak mudah ditumbuhi jamur dan bakteri pada etanol, tidak beracun, tidak bereaksi dengan komponen yang diekstraksi, absorbsinya baik, tidak membutuhkan waktu yang lama dalam pemekatan ekstrak. Selain itu, pelarut etanol dapat mengektraksi senyawa flavonoid yang tergolong dalam senyawa polar sehingga akan lebih mudah larut dalam pelarut polar (Markham,1988). Senyawa flavonoid tidak tahan terhadap pemanasan dan mudah teroksidasi pada suhu yang tinggi (Lenny, 2006), sehingga digunakan metode ekstraksi maserasi. Hasil ekstraksi maserasi didapatkan ekstrak etanol 14,5 gram.

Ekstrak etanol Begonia sp. dipartisi menggunakan dua pelarut yang mempunyai tingkat kepolaran berbeda yaitu $n$-heksana, etil asetat dan air.Hal ini bertujuan untuk memisahkan kelompok senyawa yang kepolarannya rendah ke pelarut $n$-heksana, kelompok senyawa yang kepolarannya sedang ke pelarut etil asetat dan yang kepolaranya tinggi ke air. Sepuluh gram ekstrak kental etanol benalu batu terlebih dahulu dilarutkan ke dalam $10 \mathrm{ml}$ etanol dan air $20 \mathrm{ml}$. Partisi dilakukan sebanyak 6 kali dengan jumlah pelarut $30 \mathrm{ml}$ untuk masing-masing pelarut $n$ heksana dan etil asetat. Pelarut $n$-heksana akan memisahkan senyawa-senyawa nonpolar seperti klorofil, triterpen, lemak, dan senyawa non polar lainnya sehingga memudahkan untuk mendapatkan senyawa flavonoid.Diperoleh ekstrak kental $n$-heksana sebanyak 3,40 gram dengan persen rendemen $34 \%$, ekstrak kental etil asetat 1,05 gram dengan persen rendemen $10,5 \%$ dan ekstrak air yang tersisa adalah 3,16 gram dengan persen rendemen $31,6 \%$.

Ekstrak larut $n$-heksana dan ekstrak larut etil asetat dikumpulkan, lalu diuji dengan menggunakan reaksi Shinoda dan reaksi Pew untuk memastikan ada maupun tidaknya senyawa flavonoid. Setelah diuji dengan menggunakan pereaksi shinode, ekstrak larut $n$-heksana berubah warna menjadi hijau kehitaman, dan dengan reaksi pew ekstrak $n$-heksana menghasilkan perubahan warna hijau. Hal ini menandakan tidak adanya senyawa flavonoid.Ekstrak larut etil asetat diuji dengan reaksi pew setelah penambahan serbuk magnesium dan diteteskan dengan asam klorida pekat memberikan perubahan warna merah keunguan. Dengan menggunakan metode shinode ekstrak etil asetat yang awalnya berwarna cokelat akan berwarna merah intensif selama 5 menit setelah penambahan serbuk zink dan diteteskan dengan asam klorida pekat. Hal ini menyatakan ekstrak yang larut di dalam pelarut etil asetat memiliki senyawa flavonoid (Djamil, 2014)

Proses pemisahan selanjutnya dilakukan dengan menggunakan metode kromatografi cair vakum, metode ini dilakukanpada estrak etil asetat. Metode ini didasarkan pada kecenderungan senyawa terfraksinasi berdasarkan perbedaan kepolaran pada dua fase, fase diam (silika) dan fase gerak (eluen) dengan menggunakan bantuan alat vakum. Metode ini dipilih karena kecepatan proses (efisiensi waktu) dengan cara kolom dihisap menggunakan vakum. Selain itu KCV juga dapat memisahkan komponen senyawa dalam jumlah yang banyak. Untuk proses pengelusian dilakukan dari pelarut yang nonpolar sampai dengan pelarut yang polar. Proses KCV dilakukan dengan menggunakan eluen $n$-heksana, $n$-heksana : etil asetat (3:2), $n$-heksana : etil asetat (1:4), etil asetat, etil asetat : metanol $(4: 1)$, etil asetat : metanol (3:2), etil asetat : metanol (2:3), etil asetat : metanol (1:4) dan metanol dengan masingmasing volume eluen $50 \mathrm{ml}$. Pada saat proses pengelusian awal dengan eluen $n$-heksana $100 \%$ ekstrak tidak terelusi, karena pada saat proses partisi dengan pelarut $n$-heksana, komponen yang larut sudah terpartisi sempurna sehingga komponen senyawa pada ekstrak etil asetat tidak terelusi. Setelah proses elusi selesai diperoleh delapan fraksi yaitu F2F9 dapat dilihat pada tabel 2 .

Fraksi yang diperoleh kemudian ditotolkan di lempeng KLT yang sebelumnya sudah diaktifkan untuk meningkatkan proses perembesan (elusi) oleh eluen pada silika (Sastrohamidjojo, 2007). Lempeng KLT yang 
telah ditotolkan dengan delapan fraksi, kemudian dielusi di dalam chamber dengan menggunakan eluen $n$-heksana:etil asetat (4:1) sebanyak $20 \mathrm{ml}$ dengan panjang trayek elusi 8 $\mathrm{cm}$. Setelah dielusi, lempeng KLT dikeringkan dan disemprot dengan pereaksi $\mathrm{AlCl}_{3}$. Hasil positif yang memberikan penampakan noda biru pada hasil partisi yaitu fraksi etil asetat : metanol (4:1), etil asetat : metanol (3:2), etil asetat: metanol (2:3), etil asetat : metanol (1:4) dan methanol

Uji warna yang digunakan adalah metode shinoda dan pew. Fraksi dari tiap perbandingan eluen diuji dengan menggunakan serbuk magnesium dan serbuk zink dan diteteskan dengan $\mathrm{HCl}$ pekat dan tiap fraksi memberikan perubahan warna yang berbeda-beda. Hal ini dilakukan untuk menguatkan dugaan pada metode kromatografi lapis tipis.Pada fraksi 6 terjadi perubahan warna menjadi merah tua, diduga yang terjadi karena atom $\mathrm{Mg}^{2+}$ atau $\mathrm{Zn}^{2+}$ membentuk kompleks dengan senyawa flavonoid (Andersen dan Markham, 2006). Perkiraan Komplek yang terjadi pada magnesium:

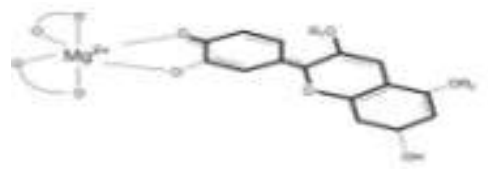

Reaksi yang dapat terjadi antara logam $\mathrm{Mg}$ dan $\mathrm{HCl}$ pekat pada pengujian flavonoid adalah reduksi inti bensopiron yang terdapat pada struktur flavonoid sehingga terjadi perubahan warna menjadi berwarna merah tua karena adanya endapan garam favillium karena terjadi reduksi dengan magnesium dan asamklorida dengan gugus $\mathrm{OH}$. Perkiraan reaksi yang terjadi (Achmad, 1986):

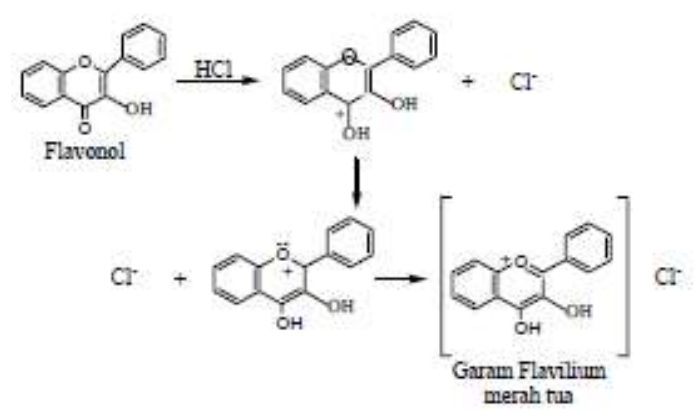

Fraksi yang diduga memiliki senyawa flavonoid tersebut dipisahkan dengan menggunakan KLTP yang ditotolkan pada lempeng kaca berukuran $20 \times 20 \mathrm{~cm}$ dan dielusi menggunakan eluen yang bersifat agak polar karena flavonoid tergolong senyawa polar sehingga lebih mudah dielusi oleh senyawa yang bersifat agak polar. Setelah dielusi didapatkan pita berwarna biru, bagian tersebut dikeruk dengan menggunakan spatula, kemudian dilarutkan menggunakan kloroform sebagai pelarut setelah itu disentrifuge selama 15 menit dengan kecepatan sentrifugasi 5000 rpm. Hal ini dilakukan agar dapat memisahkan antara komponen senyawadengan bagian silika yang ada sehingga isolat yang diperoleh tidak bercampur dengan silika.Setelah itu isolat ditampung dalam vial.

Untuk mengetahui apakah isolat benarbenar tunggal dilakukan dengan melakukan KLT multi eluen. Eluen yang digunakan dipilih berdasarkan perbedaan tingkat kepolaran yaitu $n$-heksana : kloroform : etil asetat (6:1,5:1), $n$-heksana: kloroform (3:1), dan $n$-heksana : etil asetat (4:1). Dari pengamatan pada lempeng KLT setelah dielusi dengan tiga perbandingan eluen dengan kepolaran yang berbeda, noda terlihat tunggal Seperti pada gambar 3 .

Hasil spektroskopi Ultaviolet-Visible dengan menggunakan pelarut metanol didapatkan bahwa isolat tersebut memberikan spektrum yang menyerupai senyawa flavonoid.Isolat memperlihatkan puncak spektrum pada rentang 210 - $280 \mathrm{~nm}$. Senyawa flavonoid yang terdapat pada ekstrak tumbuhan benalu batu (Begonia sp.) memperlihatkan puncak pada $275 \mathrm{~nm}$ untuk puncak 1 dan $225 \mathrm{~nm}$ untuk puncak 2 . Menurut Long Ze Lin dan Harnly James (2012) senyawa flavanol memiliki $\lambda_{\text {maks }} 278$ $\mathrm{nm}$ pada spektrofotometer UltraViolet-Visible. Hasil penelitian Achmad S.A (1998) $\lambda_{\text {maks }}$ untuk senyawa flavan-3-ol jenis afzelechin adalah 210, 242 (bahu), $286 \mathrm{~nm}$. Senyawa flavanol pada penelitian Wei - Dong Zhang (2008) dan Salim et al (2013) menyatakan $\lambda_{\text {maks }}$ flavonoid berada pada panjang gelombang 200 - 240, dan 260 - $280 \mathrm{~nm}$. Selain itu, penelitian Satolom (2015), mendapatkan bahwa senyawa dengan $\lambda_{\text {maks }}$ 231,6 dan 275,8 $\mathrm{nm}$ merupakan senyawa flavanol. Berdasarkan hasil analisis data yang dilakukan, menggambarkan bahwa senyawa flavonoid yang terdapat pada ektrak Begonia sp. diduga adalah senyawa golongan flavan-3ol. 


\section{DAFTAR PUSTAKA}

Achmad, S.A. (1986). Kimia Organik Bahan Alam. Jakarta: Karnunika.

Anam, S., Yuliet., Ritna A., Firmanita, Rismayanti D., \& Zubair M.S. (2014). Aktivitas Sitotoksik Ekstrak Metanol Benalu Batu (Begonia sp.): Ethnomedicine Suku Wana Sulawesi Tengah. Jurnal Ilmu Kefarmasian Indonesia, 12(1), 10-16.

Cindy C. S. (2015), Isolasi Senyawa Flavonoid Pada Biji Pinang Yaki (Areca vestiaria Giseke), Jurusan Kimia, FMIPA, Unsrat, Manado.

Djamil, R. (2014). Isolasi dan Identifikasi Senyawa Flavonoid dalam Fraksi nbutanol Daun Dewa (Gynura pseudochina (L.) DC) Secara Sepktrofotometer UVCahaya Tampak, Jurnal Ilmu Kefarmasian Indonesia, 12(1), 93-98.

Lenny, S. (2006). Isolasi dan Uji Bioaktifitas Kandungan Kimia Utama Puding Merah dengan Metoda Uji Brine Shrimp. FMIPA Universitas Sumatera Utara : Medan.

Lin, L.Z., \& James M. H. (2012). Quantitation of Flavanols, Proanthocyanidins, Isoflavones, Flavanones, Dihydrochalcones, Stilbenes, Benzoic Acid Derivatives Using Ultraviolet Absorbance after Identification by Liquid Chromatography-Mass Spectrometry. $J$ Agric Food Chem., 60(23): 5832-5840.

Markham, K.R. (1988). Cara Mengidentifikasi Flavonoid. Penerjemah: Padmawinata, K. Penerbit ITB, Bandung.
Novriawan, H. (2009). Sistem Pengetahuan dan Pemanfaatan Benalu Batu (Polohi Wasu) pada Masyarakat Desa Wawopada Kec. Lembo Kab. Morowali, Skripsi, Fakultas Ilmu Sosial Dan Ilmu Politik, Universitas Tadulako, Palu.

Salim, fatimah, Mazatulikhma Mat Zain, Mohd Syafiq Mohammad Ridzuan, Moses Langat, Dulcie Mulholland, and Rohaya Ahmad. (2013). Flavan-3-ols from the Leaves of Malaysian Uncaria longiflora var. pteropoda (Miq.) Ridsd. Phytochemistry Letters

Sastrohamidjojo, H. (2007). Dasar- Dasar Spektrofotoskopi, Edisi Kedua, Cetakan Kedua, Penerbit Liberty, Jogjakarta.

Sjamsul A., Achmad, Silvester, M., Udjiana, S., Aimi, N., Hakim, E.H., dan Makmur, L., (1998). Tiga senyawa flavan-3-ol dari tumbuhan Artocarpus reticulafus. Jurutan Kimia Fakultas Matematika dan 1lmu Pengetahua Alam, lnstitut Teknologi Bandung PROC. ITB, VOL. 30, NO. 2.

Zhanga, D., Sua, J., Wub, Z.J., Shena, Y.H., Zhanga, C., Lia H.L., and Liua, R.H. (2008). Three new flavanols from Daphne giraldii, Journal of Asian Natural Products Research. 10(6), 547-550.

Øyvind M. A., \& Kenneth R.M. (2006). Flavonoids Chemistry,Biochemistry and Applications, edited by CRC Press Taylor \& Francis Group, London New York 